\title{
A FAIR GLOBAL CARBON BUDGET FOR LEAST DEVELOPED COUNTRIES (LDCS)
}

\begin{abstract}
Gustavo Furini
gustavofurini@gmail.com

PhD student in International Relations: Geopolitics and Geoeconomics at the Universidade Autónoma de Lisboa (Portugal). Geographer (Universidade Federal do Rio Grande do Sul); Master's in Natural Resource Management and Local Development in the Amazon (UFPA). He is integrated Researcher at OBSERVARE - Observatory of Foreign Relations of the Universidade

Autónoma de Lisboa
\end{abstract}

\section{Abstract}

Climate change is a phenomenon recognised, monitored and researched by broad sectors of the scientific community, being one of the great challenges of the 21st century. Within this vast and transdisciplinary theme, this work discusses how the least developed countries (LDCs) can position themselves in front of the hegemonic discourse spread by the countries of the core in climate negotiations, especially in relation to the mitigation of greenhouse gases. The inductive method was adopted from a case study and information was collected from primary and secondary sources. Based on the understanding of historical emissions, climate justice and global carbon budget, it is debated here whether LDCs should actually consent to everyone's responsibilities even if they differ, since they have urgent needs to improve their development indexes, especially in terms of GDP and IDH. It is argued that the LDCs - whose historical contribution of emissions is around $0.4 \%$ of the total - should claim an increase in the share of the global carbon budget for economic and social development purposes.

\section{Keywords}

Climate Change; Historical Emissions; Global Carbon Budget; Climate Justice; Least Developed Countries (LDCs)

\section{How to cite this article}

Furini, Gustavo (2019). "A fair global carbon budget for least developed countries (LDCs)". JANUS.NET e-journal of International Relations, Vol. 10, N. ${ }^{\circ} 1$, May-October 2019. Consulted [online] on the date of the last visit, https://doi.org/10.26619/1647-7251.10.1.6

Article received on September 24, 2018 and accepted for publication on February 2, 2019 


\author{
Gustavo Furini
}

\title{
Introduction
}

Environmental issues have been the subject of debate internationally for more than four decades by the members of the United Nations (UN), with particular emphasis on the architecture for climate change negotiations initiated at the United Nations Conference on Environment and Development (UNCED) in 1992, also known as Rio de Janeiro Earth Summit (Bueno \& Pascual, 2016). This emphasis is mainly due to the scientific evidence of the Intergovernmental Panel on Climate Change (IPCC), which points to a gradual increase in the concentration of greenhouse gases in the atmosphere since the second half of the 19th century (2013). The observation confirms that phenomena arising from climate change are already occurring, to a greater or lesser extent, across the globe with potential impact on the economies and societies of all regions (ibidem). Based on the predictions and facts already observed, there is a possibility of tragedies with global dimensions occurring in the future, which postulate climate change as one of the great challenges of the 21st century (Soromenho-Marques, 2012). This is because, as one of the main consequences, the alteration of the climate system has the power to increase social disparities due to the intensification of poverty, hunger, forced human mobility, diseases, gender inequalities and greater difficulty to access natural resources. These factors ultimately limit development especially in the poorest countries, which are the most vulnerable to climate change (IPPC, 2013).

Most of the scientific community and countries part of the United Nations Framework Convention on Climate Change (UNFCCC) consider that the intensive use of fossil fuels, especially by the pioneers of the industrial revolution in Europe and the United States, is the main factor for global warming (Jönsson et al., 2012). Because of this asymmetry between rich and poor nations in terms of contributions to greenhouse gas accumulation over time, discussions within the UNFCCC have used the historical factor as a criterion for defining the principle of common but differentiated responsibilities (Shue, 2015). From this point of view, developing countries have never had formal emission reduction targets, but the failure of the developed countries to meet the targets for the first (20052012) and the second (2013-2020) periods of the Kyoto Protocol ${ }^{2}$ indicated the need for

1 The translation of this article was funded by national funds through FCT - Fundação para a Ciência e a Tecnologia - as part of OBSERVARE project with the reference UID/CPO/04155/2019, with the aim of publishing Janus.net. Text translated by Thomas Rickard.

2 During the first commitment period, industrialised countries listed in Annex B of the Kyoto Protocol committed themselves to reducing emissions by an average of $5 \%$ in relation to 1990 levels. At the Conference of the Parties (COP), held in Doha, in December 2012, the Protocol was extended to a second commitment period, from 2013 to 2020 , in which developed countries committed to reducing emissions by at least $18 \%$ below 1990 levels (UNFCCC, 2018). 
broader collaboration amongst nations (Bueno \& Pascual, 2016). For the Paris Agreement to be signed by the end of 2015, among many other formalities, all UNFCCC member states had to submit their reduction aspirations for the 2020-2030 period - the Intended Nationally Determined Contributions (INDCs) - in order to limit global warming to a maximum of 2 degrees Celsius by the end of the century (Dion \& Laurent, 2015). Although the INDCs are based on voluntary emission reduction commitments, the Paris Agreement is innovative in proposing a new arrangement in climate negotiations at the international level, as it is supported by most of UNFCCC member states to meet mitigation targets (Salinas, 2018; Bueno, 2017).

The Conferences of the Parties (COP) - international rounds in which all the UNFCCC member states participated - are not restricted to technical discussion based on scientific data, whose contribution is essential to move the negotiations forwards (Dion \& Laurent, 2015). These meetings reach their peak when the dialogues reach the political level, despite the lack of space to discuss social parameters such as those defended by climate justice (ibidem), which goes beyond the distribution of goods or environmental permits amongst nations. For the countries of the South, climate justice is imperative to avoid the permanent process of uneven development (Fischer, 2015) and it seeks to counter the hegemonic policies and measures imposed on the countries of the periphery by the countries of the core (Bond \& Dorsey, 2010).

Negotiations in multilateral organisations promise to reduce uncertainty and increase the predictability of future events. However, as a matter of course, conditions and decisions are imposed by hegemonic nations (Shadlen, 2003). As already mentioned, at the UNFCCC, multilateral talks to address and define possible gas mitigation frameworks take historical responsibility into account, but there is intense discussion to try to reformulate such a view, either from cuts based on the per capita factor - proposed by the developing countries - or on the current profile of total emissions as rich countries want (Parks \& Roberts, 2008).

Historical responsibility represents the "polluter pays" principle. Although it protects those who least polluted - at least in theory - on the other hand, it did not penalise those who historically most emitted greenhouse gases. The per capita approach advocates the equalitarian principle that everyone should have equal rights to global public goods, including atmospheric stability (Randalls, 2011). But as part of the industries have been shifted from the centre to the periphery in recent decades (Wallerstein, 2004), this approach must be used carefully as the per capita contribution of the Southern countries (Shue, 2015) have been increasing. This caution regarding the migration of industries, especially with the advancement of globalisation in the 21st century, is reinforced by the discourse of rich countries defending current total emissions as a single parameter for reduction.

The different perceptions about climate justice are constructed and perceived to a large extent by the highly unequal positions that the countries occupy in the global hierarchy, materialised by their economic and political power (Randalls, 2011). The fundamental political issue of the current negotiations is around who should make cuts and who can continue to emit, considering that the stock of greenhouse gases accumulated in the atmosphere is largely the responsibility of rich and industrialised countries (Parks \& Roberts, 2008). The notion of a global carbon budget, in which part of the quota has already been used over time and another is committed to meeting the objectives of international climate agreements, is fundamental to the debate on climate change. 
Data on greenhouse gas emissions clearly demonstrate the dissonance between emissions over time between rich and poor countries, as well as increasing participation in emissions from developing countries, especially those that have undergone the last industrialisation process, such as the $\mathrm{BASIC}^{3}$ countries. It is a challenge for developing nations to address the issue of climate change domestically, as the attention of these governments is still focused on ensuring better economic and social conditions for their people. The discourse that all countries must take action to curb emissions, including those that have serious difficulties in guaranteeing basic conditions and rights to their population - such as the Least Developed Countries (LDCs) ${ }^{4}$ - does not seem feasible, at least in the short term.

Thus, the guiding question of this essay is: What stance should the LDCs countries adopt in relation to the global carbon budget and under what justification? It was based on a (i) bibliographic review of books, publications, journals and scientific magazines and the (ii) collection, sampling, systematisation and analysis of qualitative and quantitative official $^{5}$ data available on the world computer network for the elaboration of graphs and figures. In addition to this introduction, this essay has three sections to approach theoretical frameworks involving: global carbon budget, historical responsibilities and climate justice. The end contains discussion on climate justice for LDCs and final considerations.

\section{Climate change and the global carbon budget}

The consensus in the scientific community is that human activities interfere in the energy balance of the planet as a result of the continuous and increasing greenhouse gas emissions, and the global warming process is evidenced by the analysis of data collected in the atmosphere, earth, ocean and ecosphere (IPCC, 2013). From the analysis of data collected in several stations scattered around the planet, it is possible to verify the variation in the temperature of the terrestrial and oceanic surfaces and, as a consequence of the increase in global average temperature, there are higher rates of: melting glaciers and polar caps, rising sea levels and acidification, rising heat waves and areas prone to desertification, greater intensity and constancy of extreme weather events (ibidem).

Since the 1990s, UNFCCC efforts have been focused on mitigating greenhouse gas emissions in order to meet the UNFCCC's ultimate goal of stabilising atmospheric concentrations of these gases to prevent human actions from interfering in a dangerous way in the climate system (Matthews et al., 2012). As a result of climate modelling research, developed with the intention of estimating emission reduction efforts to meet emission targets, the idea that future scenarios should be evaluated based on a global carbon budget was developed (Collins et al. 2013 apud Gignac \& Matthews, 2015; IPCC, 2013). Such budget was structured from the understanding that changes in climate are directly related to cumulative carbon emissions over time, i.e. by the sum of historical emissions with current and future emissions (Matthews et al., 2012). In this way, it is

3 Brasil, South Africa, India and China.

4 Designation given by the United Nations to the group of low-income countries that face severe structural impediments to sustainable development and are highly vulnerable to economic and environmental shocks due to low human capital. Accessed on September 10, 2018. Available at https://www.un.org/development/desa/dpad/least-developed-country-category.html.

5 Source of primary data: The World Bank, UNFCCC e United Nations Development Programme (UNDP). 
possible to determine the global temperature by relating it to the quantity of cumulative emissions produced in a given period (Gignac \& Matthews, 2015). In order to limit global warming to a maximum of $2^{\circ} \mathrm{C}$ by 2100 , a global carbon budget of around $1,000 \mathrm{PgC}^{6}$ or $1,000 \mathrm{Gt}$ should be considered, but by 2011 about half of this budget was already committed (IPCC, 2013).

The global carbon budget given by greenhouse gas accumulation presents itself as an alternative to plan and negotiate the climate agenda (Matthews et al., 2012). After the agreement amongst the scientific community regarding the quantities and who are the responsible for cumulative emissions, the next step is to agree on mitigation efforts based on the division of the global carbon budget (Gignac \& Matthews, 2015). The criteria for future emissions sharing are not yet defined, but there are some proposals founded on three pillars: current emissions data, historical emissions and per capita division (ibidem). Criteria based on historical and per capita emissions safeguard developing countries, which include the LDCs, whilst decisions based on current emissions will further protect the interests of rich countries, bearing in mind that much of the global industry has been - and still continues to be - displaced from the core to the periphery.

\section{Historical responsabilities}

Due to their physicochemical characteristics, greenhouse gases have a long residence time in the atmosphere and, therefore, they take hundreds of years until they are naturally dissipated (IPCC, 2013). Taking this into account, a central issue in the discussions on climate change is whether nations that have polluted in the past should be held accountable for emissions that are still in the atmosphere and then bear the costs of future mitigation actions (Hayner \& Weisbach, 2016). What is at stake is equity when sharing the responsibility for emissions, or historical responsibility, which is the moral and legal responsibility for past emissions. This is a fundamental discussion, although some governments try to advocate the contrary (Shue, 2015).

There is heated debate amongst those who understand that historical emissions should be framed as misappropriation of a common good - in this case, the atmosphere and thus precepts of climate justice should be applied. On the other hand, others refute the theory of appropriation, arguing that in the past there was no awareness of the potential damage caused. Consequently, there was no bad intention (Schüssler, 2011) on the grounds of "excusable ignorance" of the acts (Bell, 2011). This last trend argues that the principles of distributive or corrective justice should not be used in climate negotiations to try to solve problems of unfair distribution of wealth, and the market should be in charge of this task (Bernstein, 2016). On the other hand, climate justice seeks to counteract the policies formulated by the Northern countries for not believing the market promises to solve the problem, as its only concerned is to maintain the status quo of hegemony and centre-periphery relations (Fischer, 2015; Bond \& Dorsey, 2010).

Even though polluter countries did not intend to harm the environment, both present and future generations benefit from previous actions taken by their nation, since this is a continuous entity of which individuals are a part (Shue, 2015). A nation has "continuing structures and institutions; past, present, and future members are primary beneficiaries

6 According to IPCC's table, 1P (Peta) $=10^{15}$. Accessed on September $20^{\text {th }}, 2018$. Available at http://www.ipcc.ch/ipccreports/tar/wg3/ index.php?idp $=477$. 
of these on-going national formations and practices" (Shue, 2015: 14). The fact that a citizen is born in a rich and industrialised nation makes their life potentially healthier and full of opportunities and choices, unlike those born in a poor and non-industrialised nation whose individuals experience various privations that directly affect their freedoms of choice (Sen, 2001).

Due to the bonus obtained by pioneering industrialisation, justice related to the burden of current and future greenhouse gas mitigation costs should be based on three principles: (i) unequal burdens, (ii) greater ability to pay and (iii) guaranteed minimum (Shue, 2014: 13-14). The first principle considers that whilst some parties have gained an unfair advantage over others in the past - by imposing environmental costs without prior consent - those who have been unilaterally placed at a disadvantage have the right to demand responsibilities to be measured, in the future, according to the previous unjust advantage, so that fairness can be restored. The second one, greater ability to pay, relates to richer countries, given their greater financial conditions they must give more. Finally, the guaranteed minimum refers to the human factor as when some people do not have access to the basic conditions for a decent life and, on the other hand, some have much more than enough, it is unfair not to guarantee everyone at least an adequate minimum - although some will still have more than others (ibidem).

\section{Focus on climate justice}

It is important to emphasise that the discourse of the hegemonic trend that defends the rich countries usually prevails (Shadlen, 2003). Thus, with regard to climate change, usually the countries of the centre try to evade any responsibility for past emissions based on the argument of "excusable ignorance" of the acts. To do so, they argue that only a little more than three decades ago the first discoveries were made about the harmful effects of man-made greenhouse gases on the atmosphere (Bell, 2011). However, the apology for ignorance of the risks claimed by the Northern countries is questionable.

It is questionable because the knowledge and studies on the effects of anthropic interference on the climate were being already investigated by Svante Arrhenius in the late 19th century (Rodhe et al., 1997). The Swedish scientist was the first to establish a quantitative link between changes in $\mathrm{CO}_{2}$ concentration caused by industrialisation and the possible impacts on the climate. And in April 1896 he published a paper in a British philosophical magazine with the results obtained at the time (Uppenbrink, 1996). In addition, since the 1950s, just after the Second World War, a sophisticated $\mathrm{CO}_{2}$ measuring station on the island of Mauna Loa, in Hawaii, was used to continually collect, register and monitor data related to changes in concentration of gases in the atmosphere (NOAA). ${ }^{7}$ There is also a study on the ice cores collected on the Antarctic from the 1960s, which demonstrates the tendency of a sharp increase in $\mathrm{CO}_{2}$ levels from the propagation of industrial activity in the Northern countries in the 19th century (Lüthi et al., 2008).

Climate justice emerges as a movement of political and social claim from the unfolding of environmental justice and the understanding that the impacts of climate change

7 The National Oceanic and Atmospheric Administration (NOAA) is the scientific agency of the USA in charge of monitoring the oceans and atmosphere conditions. Accessed on September 15th, 2018. Available at https://www.esrl.noaa.gov/gmd/obop/mlo/. 
unequally affect different social groups, with the economically least privileged being the most vulnerable (Newell \& Mulvaney, 2013). The climate issue was able to bring together actors with or without a history of action related to environmental issues given their global scope, and climate justice has its main stage of protest precisely in the international sphere (Milanez \& Fonseca, 2011). In addition, the lack of the global elite's ability to solve the major environmental, social and economic biases - the tripod of sustainable development, according to the Brundtland Report of 1987 - generated a demand for the incorporation of other elements and dimensions to climate justice, such as: ethics, moral, philosophy, ideology, strategies and tactics (Bond, 2011).

The term climate justice, or even distributive justice, entered the UNFCCC discussions through the effort made by the Southern countries based on the different historical responsibilities (Fischer, 2015), since they have a high degree of social, economic and environmental vulnerability as well as a limited capacity to adapt to climate impacts (IPCC, 2013). Amongst the political and ideological positions of climate justice, the one that advocates greater participation in the global carbon budget for peripheral countries stand out, taking into account their urgent need for development (Fischer, 2015; Bond, 2011).

\section{Climate justice to LDCs}

The $\mathrm{LDCs}^{8}$ is a specific group of low-income developing countries which have a number of structural impediments to economic growth and social development, requiring special measures to address challenges faced (UN-DESA, 2018). Currently, the LDCs account for about one billion people, but contributed with only $0.4 \%$ of the total volume of gases accumulated in the atmosphere over the last five decades ${ }^{9}$ (Figure 1), whilst highincome ${ }^{10}$ countries contributed with more than half of the emissions in the same period. Thus, based on historical emissions (Randalls, 2011; Bond \& Dorsey, 2010) and assumptions about climate justice (Fischer, 2015; Bond, 2011), the LCDs seem to have the legitimate right to claim a substantive increase in their participation in the global carbon budget (BASIC Experts, 2011). If we analyse the period between 1850 and 2000, the discrepancy between emissions from Northern and Southern countries is even more abysmal, since it is estimated that during this period $79 \%$ of global emissions were released into the atmosphere by rich countries (ibidem).

8 The 47 countries of the LDC group are: Afghanistan, Angola, Bangladesh, Benin, Burkina Faso, Burundi, Bhutan, Cambodia, Chad, Comoros, Djibouti, Eritrea, Ethiopia, Gambia, Guinea, Guinea Bissau, Haiti, Yemen, Solomon Islands, Kiribati Laos, Lesotho, Liberia, Mozambique, Madagascar, Malawi, Mali, Mauritania, Myanmar, Nepal, Niger, Central African Republic, Democratic Republic of the Congo, Rwanda, Sao Tome and Principe, Senegal, Sierra Leone, Somalia, Sudan South Sudan, Timor-Leste, Togo, Tuvalu, Uganda, Tanzania, Vanuatu and Zambia. Accessed on December $9^{\text {th }}, 2018$. Available at https://www.un.org/development/desa/dpad/least-developed-country-category/LDCSs-at-a-glance.html.

9 Data available at https://data.worldbank.org/indicator/EN.ATM.GHGT.KT.CE. Accessed on August 15th, 2018.

10 The group of 78 countries classified by the World Bank as "high income" have an annual per capita income of more than 12,236 USD and are mostly represented by rich countries of North America and Europe. 
Figure 1. Cumulative $\mathrm{CO}_{2}$ emissions - totals and percentage values (1960-2014)

\section{Emissions of $\mathrm{CO} 2$ accumulated in the atmosphere}

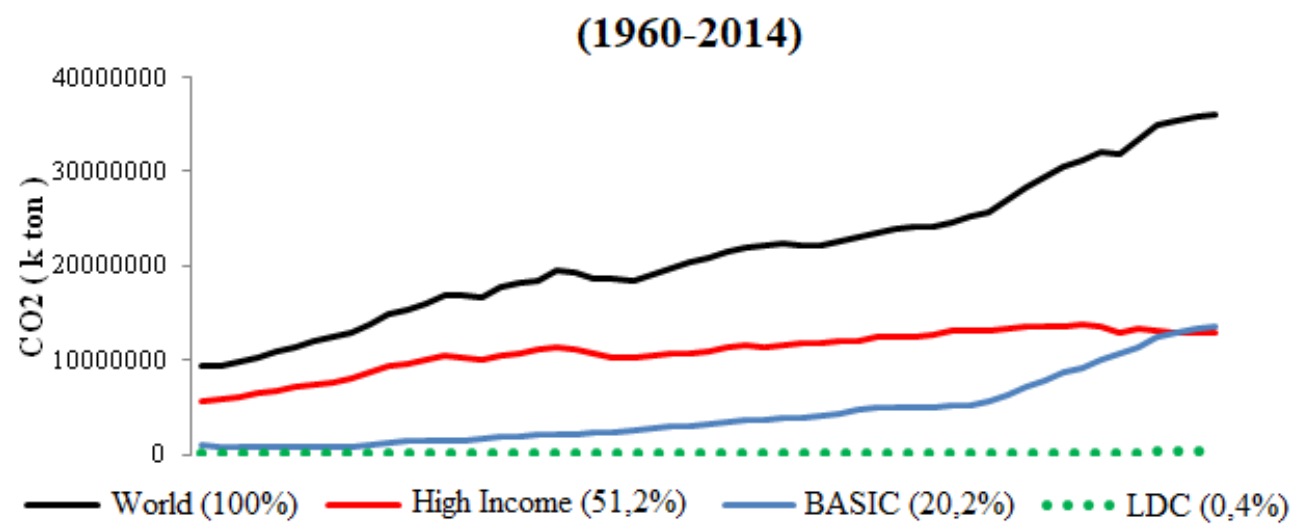

Source: Elaborated by the author from World Bank data.

On the grounds that everyone deserves a decent life (Shue, 2014) - even though by increasing emissions at first - the LCDs should reinforce the call for greater participation in the global carbon budget involving current and future emissions. From the perspective of global sustainability, it is true that emissions should be reduced by humanity as a whole (BASIC Experts, 2011), and the countries of the core should bear the greatest costs due to historical ecological debt (Parks \& Roberts, 2008).

Considering that LDCs have a historical tendency to emit only $0.4 \%$ of total greenhouse gases, if they increase their emissions by 10 times, for example, the rest of the world would have to reduce its emissions to $46 \%$ of the current total. Therefore, global emissions would reduce by half. It seems legitimate, under the precepts of climate justice, that the countries of the core reduce their emissions to such an extent that LDCs could emit more and thus be able to improve their Gross Domestic Product (GDP) and Human Development Index (HDI). It is not about giving the LDCs the right to pollute, but fairly sharing the global carbon budget (Pan \& Chen, 2010).

Regarding future reductions, some developing countries - especially those part of the BASIC - indicate that they will negotiate some share due to the upward trend from the 1990s (BASIC Experts, 2011). However, it should be noted that most of the emissions are related to the migration of industries from the core to the periphery (Parks \& Roberts, 2008). It is also worth mentioning that the BASIC has presented a propositional stance in the UNFCCC rounds, demonstrating that its members aim to play a leading role in climate negotiations (Hallding et al., 2013). Nevertheless, within the group of developing countries, the BASIC has more abilities than LDCs in several aspects, including economic capacity.

For climate justice and with a focus on greater participation in the global carbon budget for the LDCs, its member states should continue to pursue economic and social development as a priority goal rather than investing meagre resources in mitigation actions, at least for now. The participation of all, even if in a differentiated and voluntary way, does not seem to be justifiable considering the urgent need to improve the basic 
living conditions of these countries' populations. Low HDI values in the LDCs - historically always below 0.5 on an optimal scale with 1 - reinforce this need (Figure 2 ). ${ }^{11}$

Figure 2. Evolution of the average HDI of the LDCs (1990-2015).

\section{HDI Average - LDC group (1990-2015)}

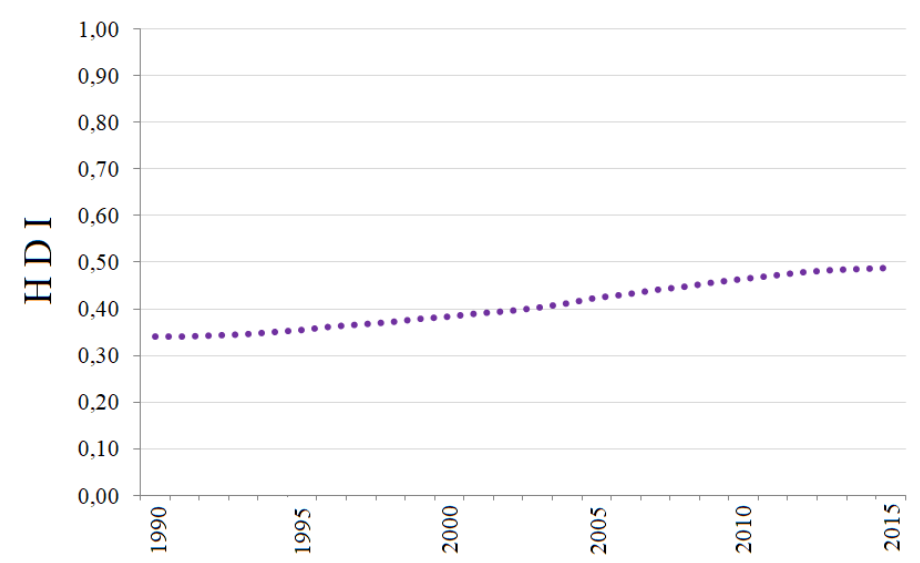

Source: Elaborated by the author from the UNDP data.

In addition to the HDI, LDCs need to increase their GDP levels in order to foster public investments and reduce social gaps. To give an idea of the discrepancy between GDP values in the international scenario, the average per capita GDP of LDCs represented only $3 \%$ of the average values obtained in high-income countries over the last three decades (Figure 3). ${ }^{12}$

Figure 3. A) Average per capita GDP of high-income countries, the BASIC (1960-2016) and LDCs (1985-2016). B) Per capita GDP of LDCs (1985-2016).

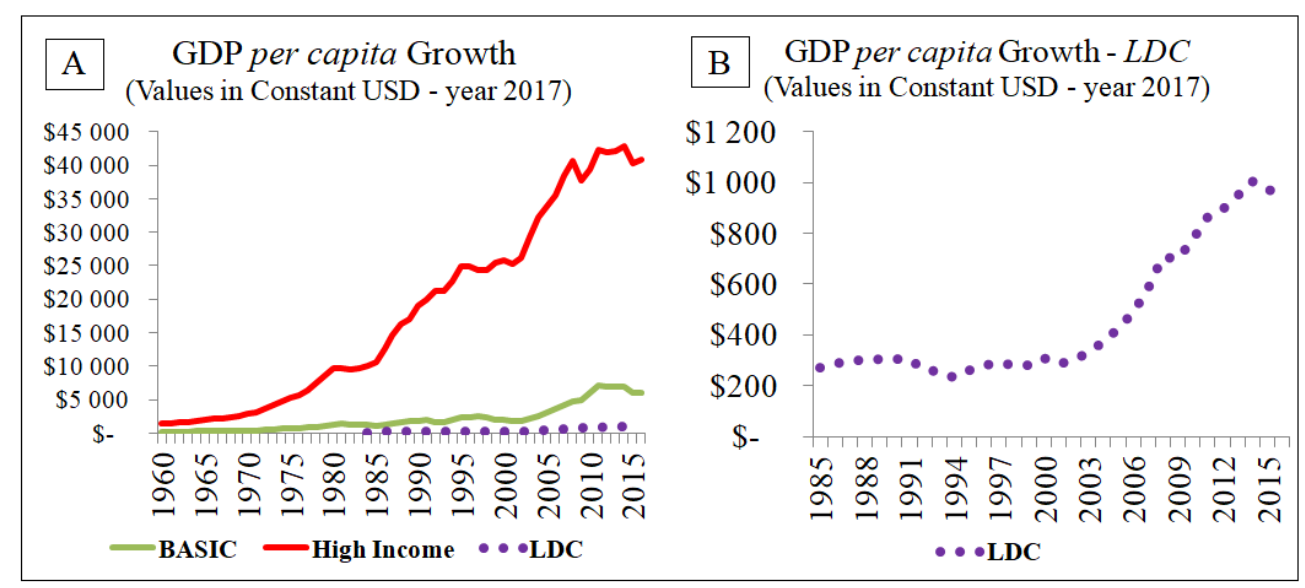

Source: Elaborated by the author from World Bank data.

11 Data available at: http://hdr.undp.org/en/content/human-development-index-hdi. Accessed on August 25th, 2018.

12 Data available at: https://data.worldbank.org/indicator/NY.GDP.MKTP.CD. Access in August 20th, 2018. 
A transition to a low-carbon economy requires investments that peripheral countries cannot make at the moment, so any action that need to use new technologies should be funded by core countries. In 2015, during the preparations for the Paris Agreement, all countries had to submit their reduction intentions for the 2020-2030 period to the UNFCCC, including the LDCs (Figure 4). Although all member states part of the LDCs need external support for mitigation measures, it does not seem reasonable for 23 countries - about half of them - to fit into the hegemonic discourse of the North and to accept sharing responsibilities by investing part of the narrow and committed public budget in mitigation actions to combat the climate crisis originated by countries of the centre ${ }^{13}$.

Figure 4. Intended nationally determined contributions (INDCs) in the scope of the UNFCCC.

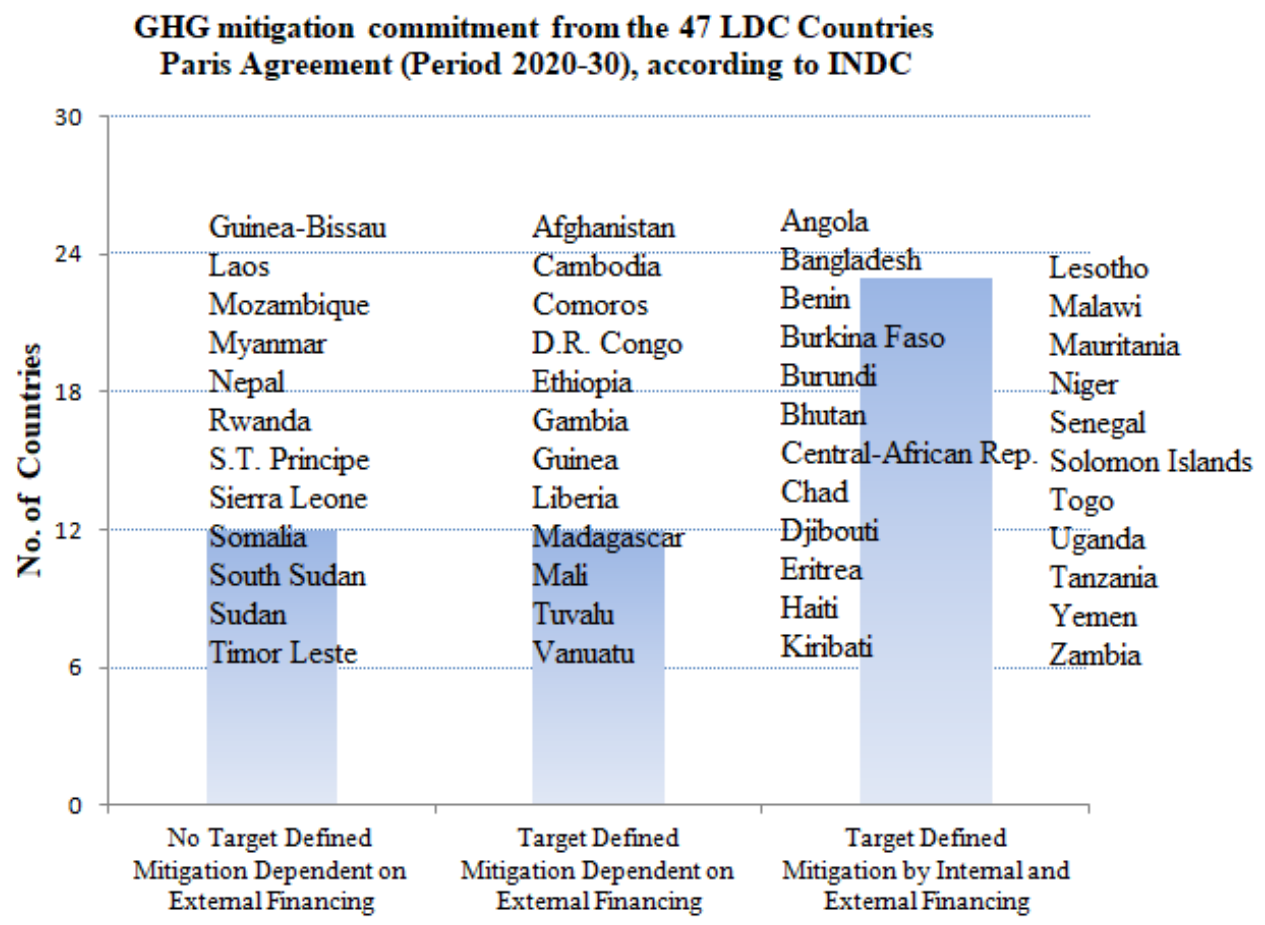

Source: Elaborated and systematised by the author based on the analysis of the LDCs by the INDCs.

The data presented in Figure 4 show that developing countries are concerned and committed to sustainability due to their vulnerability to climate nuances. Multilateralism almost always has a high price for the periphery (Shadlen, 2003) and the eternal dependence makes these countries accept any promise of aid. Periphery countries should not position themselves in such a way as to sacrifice their sovereignty by committing themselves to the decisions of multilateral institutions, whilst the countries of the centre do not even do their part (ibidem). This reality also seems opportunely applicable to the

13 Data available at: https://www4.unfccc.int/sites/submissions/INDC/Submission\%20Pages/ submissions.aspx. Access in August 1st, 2018. 
UNFCCC, as peripheral countries, by accepting the hegemonic discourse, seem to fulfil their role as extras when expressing good intentions to help solve a problem that they did not cause. Not to mention that it is precisely the poor countries that are most vulnerable to the impacts of climate change (IPCC, 2013).

In response to the challenges posed by climate change, even though rich countries have committed themselves to establishing a climate fund within the UNFCCC, it does not seem to be working as expected. During the 2009 and 2010 Conference of Parties (COP), held in Copenhagen and Cancun, Northern countries formally agreed to jointly mobilise around 100 billion USD per year by 2020. To this end, the Green Climate Fund (GCF) has been created, which is an initiative to help developing countries mitigate and adapt to climate change. ${ }^{14}$ However, the donations made are far from the promised amount. According to GCF official data ${ }^{15}$ from 2010 to 2017 just over $10 \%$ of what had been promised for a single year was collected.

\section{Final considerations}

As the atmosphere is a public natural resource of all humanity (Salinas, 2018; Randalls, 2011), unequal allocation of the global carbon budget cannot be a means to restrict the development of peripheral countries (Teng et al., 2011). The gases accumulated in the atmosphere, mostly released by developed countries, led to global warming and nothing fairer than the centre taking responsibility for it (Mesík, 2016). Instead of consenting to the hegemonic discourse of everyone's commitment to mitigation right now, peripheral countries need to ensure, in the first instance, better living conditions for their population. From the perspective of climate justice, the imposition of unfair logics on the periphery should be ignored by the LDCs, who should require developed countries to adopt lesspolluting models urgently to resolve the climate crisis generated by the core countries.

This essay considers that, during the global carbon budget negotiations, LDCs should demand a multi-fold increase in their quota, since their contribution over almost six decades - from 1960 to the present - is only $0.4 \%$ of the total generated and accumulated in the atmosphere. LDCs should abandon the consent stance of the hegemonic discourse of the UNFCCC negotiations and not take mitigation actions in the short and medium term. It is true that global emissions need to be reduced as a whole, but it seems to us that it is not the time yet for LDCs to help pay that bill. This is because the increase in the share of the global carbon budget will help the LDCs to start the much needed economic and social development, since traditional technologies are still economically more viable, even though they are carbon-intensive. To demand these countries to use clean technologies for social and economic development seem to be out of common sense and impossible in practice.

It is also argued here that LDCs, when having a broad participation in the global carbon budget, share their quota among their members. That is, due to the group's heterogeneity, if any country needs to emit more gas than expected, bilateral or multilateral partnerships between its members are recommended. In addition, SouthSouth partnerships with other peripheral or semi-peripheral countries are welcome to

14 Accessed on September 15th, 2018. Available at https://www.greenclimate.fund

15 Accessed on September 15th, 2018. Available at https://www.greenclimate.fund/documents/20182/24868/Status_of_Pledges.pdf 
avoid perpetuating the process of dependency. Nonetheless, it is obviously interesting for sustainable development purposes if rich countries are willing to install cleaner technologies in the LDCs member states from fully funded, subsidised and paid investments from the North. Agreements in which the host country is contractually obligated to bear part of the investments and also to pay high interest by the centre should be avoided.

In addition, the LDCs should not be seduced by the hegemonic discourse of the centre and allow their part of the global carbon budget to be compromised through the export of emissions from the centre to the periphery by establishing polluting factories. This centre-periphery migration movement of greenhouse gases, under the pretext of generating jobs, income and local development, has been very common in the relationship with the semi-periphery, which eventually became the world-system factory locomotive. Clean industries can be exported, provided they are installed in compliance with environmental standards, paying decent wages and generating revenue to the receiving country from the full payment of taxes. The pioneers of these technologies must be the rich ones who, whilst developing and lowering their cost, can then foster their use in the poorest countries of the planet.

\section{References}

BASIC Experts (2011). Equitable access to sustainable development: Contribution to the body of scientific knowledge. BASIC expert group: Beijing, Brasilia, Cape Town and Mumbai.

Bell, D. (2011). Global climate justice, historic emissions and excusable ignorance. In The Monist, Vol. 94, No. 3, pp. 391-411.

Bernstein, A. R. (2016). No justice in climate policy? Broome versus Posner, Weisbach, and Gardiner. In Midwest Studies in Philosophy, Vol. 40: 1, pp. 172-188.

Bond, P. \& Dorsey, M. K. (2010). Anatomies of environmental knowledge and resistance: diverse climate justice movements and waning eco-neoliberalism. In Journal of Australian Political Economy.

Bond, P. (2011). Politics of climate justice: paralysis above, movement below. Apresentado ao Gyeongsang University Institute of Social Science, May $27^{\text {th }} 2011$, Jinju, South Korea.

Bueno, M. P \& Pascual, G. (2016). International climate framework in the manking: the role of the Basic Countries in the negotiations towards the Paris Agreement. In JANUS.NET e-journal of International Relations, Vol. 7, No. 2.

Bueno, M. P. (2017). El Acuerdo de París: ¿una nueva idea sobre la arquitectura climática internacional? In Relaciones Internacionales, No. 33, pp. 75-95.

Dion, S. \& Laurent, E. (2015). Climate action beyond Paris Accord. Working Paper 201522. OFCE. Paris.

Fischer, S. (2015). The emerging geographies of climate change. In The Geographical Journal, Royal Geographical Society, Vol. 181, No. 1, pp. 73-82.

Gignac, R. \& Matthews, H.D. (2015). Allocating a $2{ }^{\circ} \mathrm{C}$ cumulative carbon budget to countries. In Environmental Research Letters. Vol. 10. IOP Publishing. 
Hallding, K., Jürisoo, M., Carson M. \& Atteridge, A. (2013). Rising powers: the evolving role of BASIC countries. In Climate Policy, Vol.13, No. 5, 608-631.

Hayner, M. \& Weisbach, D. (2016). Two theories of responsibility for past emissions of carbon dioxide. In Midwest studies in Philosophy. Vol. 40. pp 96-113.

IPCC (2013). The Physical Science Basis. Fifth Assessment Report.

Jönsson, K., Jerneck, A. \& Arvidsson, M. (2012). Politics and development in a globalised world: an introduction. Lund: Studentlitteratur.

Lüthi, D., et al. (2008), High-resolution carbon dioxide concentration record 650,000800,000 years before present, In Nature, Vol. 453, pp. 379-382.

Matthews, H. D., Solomon, S. \& Pierrehumbert, D. (2012). Cumulative carbon as a policy framework for achieving 1 climate stabilization. In Philosophical Transactions, Vol. 370, pp. 4365-79.

Mesík, J. (2016). Climate Change: threats and Challenges. Cenker, M., Hadjivasiliou, L., Marren, P., Rooney, N. (Orgs). In Development Education: in theory and practice. UNIDEV.

Milanez, B. \& Fonseca, I.F. (2011). O discurso da justiça climática no contexto brasileiro: possibilidades e perspectivas. Motta, R.S., Hargrave, J., Luedemann, G., Gutierrez, M.B.S. (Orgs), In Mudança do clima no Brasil: aspectos econômicos, sociais e regulatórios. Brasília: Ipea.

Newel, P. \& Mulvaney, D. (2013). The political economy of the 'just transition'. In The Geographical Journal. Royal Geographical Society.

Pan, J, \& Chen, Y. (2010). Carbon budget proposal. In Pachauri, R. K. (Org). Dealing with Climate Change: setting a global agenda for mitigation and adaptation. Nova Déli: Tery Press.

Parks, B. \& Roberts, T. (2008). Inequality and the global climate regime: breaking the north-south impasse. In Cambridge Review of International Affairs, Vol. 21, No. 4. pp. 621-48.

Randalls, S. (2011). Broadening debates on climate change ethics: beyond carbon calculation. In The Geographical Journal, Royal Geographical Society, Vol. 177, No. 2, pp. 127-37.

Rodhe, H., Charlson, R. \& Crawford, E. (1997). Svante Arrheniys and Greenhouse Effect. In Ambio, Vol.26, No. 1, pg. 2-5.

Salinas, S. (2018). El acuerdo de Paris de diciembre de 2015: la substitución del multilateralismo por la multipolaridad en la cooperación climática internacional. In Revista Española de Derecho Internacional - REDI, Vol. 70/1, pp. 53-76.

Schüssler, R. (2011). Climate justice: a question of historic responsibility? In Journal of Global Ethics, Vol. 7, No. 3, pp. 261-78.

Sen, A. (2001). Development as Freedom. Oxford: Oxford University.

Shadlen, K. (2003). Patents and Pills, Power and Procedure: The North-South Politics of Public Health in the WTO. In Developing Studies Institute - DESTIN, London School of Economics and Political Science, No. 03-42. 
Shue, H. (2014). Climate Justice: Vulnerability and Protection. Oxford: Oxford University Press.

Shue, H. (2015). Climate Historical Responsibility, Harm Prohibition, and Preservation Requirement: Core Practical Convergence on Climate Change. In Moral Philosophy and Politics, De Gruyter, Vol. 2, pp. 7-31.

Soromenho-Marques, V. (2012). Alterações climáticas - a verdadeira crise do século XXI. In JANUS.NET e-journal of International Relations, Vol. 3, No. 2, pp. 175-78.

Teng, F., Jiankun, H., Xunzhang, P. \& Zang, C. (2011). Metric of carbon equity: carbon Gini Index based on historical cumulative emission per capita. In Advances in Climate Change Research, Vol. 2, pp. 134-40.

UN/DESA, Department of Economic and Social Affairs of the United Nations Secretariat. (2018). Handbook on the Least Developed Country Category: Inclusion, Graduation and Special Support Measures. Third Edition, United Nations.

UNFCCC (2018). Doha Amendment to the Kyoto Protocol. XXVII 7 C. ENVIRONMENT.

Uppenbrink, J. (1996). Arrhenius and Global Warming. In Science, Vol. 272, pp. 1122.

Wallerstein, I. (2004). World System Analysis: an introduction. London: Duke University Press. 